\title{
Selenium Supplementation and Cancer Prevention
}

\author{
Cindy D. Davis
}

Published online: 7 January 2012

(C) Springer Science+Business Media, LLC (outside the USA) 2012

\begin{abstract}
The essential trace element selenium has been shown to have cancer preventive potential by a converging body of epidemiologic and preclinical studies. Although randomized controlled trials suggest a benefit against liver cancer, results at other sites are not as consistent. The Nutritional Prevention of Cancer Trial provided evidence that selenium-enriched yeast can protect against total cancer incidence and the incidence of prostate, lung, and colorectal cancer. In contrast, in the Selenium and Vitamin E Cancer Prevention Trial (SELECT), selenomethionine provided no protection against prostate, lung, or colorectal cancer. Results from these trials suggest that the cancer protective effects of selenium probably depend on the baseline selenium status of the individual, chemical form of selenium utilized, gender, and genetic polymorphisms in selenoproteins or in cancer-related processes.
\end{abstract}

Keywords Selenium · Selenoproteins · Cancer prevention . Nutritional prevention of cancer trial · SELECT trial · Supplementation

\section{Introduction}

Selenium (Se) is 1 of about 60 essential dietary components for animals and humans. Our understanding of the

\section{D. Davis $(\bowtie)$}

Division of Cancer Prevention, Nutritional Science Research Group, National Cancer Institute,

6130 Executive Boulevard, Suite 3159,

Rockville, MD 20892-7328, USA

e-mail: davisci@mail.nih.gov significance and complex metabolic role of Se in human nutrition has evolved substantially in the past century. Historically, Se was regarded as a naturally occurring toxic element causing signs in farm animals such as loss of hooves and hair, emaciation, stiffness, and even death [1], and was reported to be a carcinogen [2]. However, this perspective has undergone radical transformation in the past 50 years. The pioneering work of Schwarz and Foltz [3] demonstrated the nutritional essentiality of Se when a component containing Se was found to prevent hepatic necrosis in rats consuming a torula yeast- and vitamin E-deficient diet. This led to the realization that Se deficiency was responsible for several disorders observed previously in animals (eg, white muscle disease) as well as a contributing factor to Keshan disease in humans. The suggestion that $\mathrm{Se}$ might also have a cancer protective role occurred almost a decade later when an inverse relationship was observed between cancer mortality rates and forage crop Se concentrations in the United States [4]. However, conclusive evidence for a metabolic role of Se came in 1973 with the discovery that $\mathrm{Se}$ is an essential component of glutathione peroxidase, an enzyme that protects against oxidative injury [5]. Most of the known metabolic functions of Se are associated with specific selenoproteins; however, it can also react with thiols. Twenty-five selenoproteins have been identified in the human genome [6]. These include the glutathione peroxidases, thioredoxin reductases, and thyroid hormone deiodinases, as well as several uncharacterized selenoproteins. Many of the selenoproteins catalyze redox reactions with Se at the active site. This redox activity has led to the hypothesis that this essential nutrient has a natural role in cancer prevention. This review focuses on $\mathrm{Se}$ requirements, metabolism, and the evidence to suggest that 
it has a role in cancer prevention, as well as why clinical studies with Se have not always yielded positive results.

\section{Selenium in Diet and Food}

Diet is the predominant source of Se in humans, but it also can be derived from drinking water, environmental pollution, and supplementation. The Recommended Dietary Allowance for Se is $55 \mu \mathrm{g} / \mathrm{d}$ for healthy adults [7]. Average Se intake in the United States is $122 \mu \mathrm{g} / \mathrm{d}$ [8]. Dietary sources of Se include grains, meat, eggs, dairy products, vegetables, and seafood-accounting for more than half of the dietary Se intake [9]. Most Se in plants is selenomethionine (SeMet), whereas in meat, it can be found as SeMet or selenocysteine (SeCys) [10, 11]. Although SeMet and Se-enriched yeast are widely used in over-the-counter nutritional supplements, infant formulas and parenteral feeding mixtures contain $\mathrm{Se}$ in the form of sodium selenate or sodium selenite, even though these are not nutritional forms of Se [12]. Several intervention studies have used Se-enriched yeast as the source of supplemental Se.

Se enters the food chain through plants, and its concentration in foods is subject to several factors that are directly related to the amount and bioavailability of Se in the soil [13]. Most plants contain only low foliar concentrations of $\mathrm{Se}$, less than $25 \mu \mathrm{g} / \mathrm{g}$ dry weight, and rarely exceed $100 \mu \mathrm{g} / \mathrm{g}$ dry weight, even when grown on high-Se soils [14]. However, a limited number of specialized plants, which are often found growing on soils that are naturally enriched in Se, can accumulate high concentrations of Se in their foliage. The best characterized Se accumulator plant is Astragalus, which can accumulate 1-10 $\mathrm{mg}$ of Se per gram [15]. Food plants can also be induced to accumulate Se. Fertilization techniques have been used to grow garlic that contains more than $1300 \mu \mathrm{g} / \mathrm{g}$ of Se [16]. This property of certain species of plants to accumulate Se has been employed in phytoremediation efforts, which use plants to decontaminate environmental Se pollution in soil and water $[17,18]$.

Selenium is required in the diet but can be toxic if consumed in excessive amounts. The US Food and Nutrition Board of the Institute of Medicine has set a Tolerable Upper Intake Level for Se at $400 \mu \mathrm{g} / \mathrm{d}$ [7]. Chronic toxicity of Se in humans results in a condition termed selenosis, characterized by hair and nail loss and brittleness, gastrointestinal problems, skin rash, garlic breath odor, and nervous system abnormalities [19]. The US Environmental Protection Agency correlated the whole blood Se level at which clinical selenosis occurred $(1.35 \mathrm{mg} / \mathrm{L})$ with a $1.26 \mathrm{mg} / \mathrm{d}$ intake of $\mathrm{Se}$ [20]. It is generally accepted that inorganic forms of Se are more acutely toxic than organic forms such as SeMet or Se-enriched yeast because of differences in their metabolism $[12,21]$.

\section{Selenium Metabolism}

The cellular responses induced by Se compounds are very diverse and are influenced by the chemical form and dose of Se. Se undergoes extensive metabolism in animals, as previously reviewed $[19,22]$. The major plant form of Se, SeMet, is absorbed in the small intestine with high affinity via the $\mathrm{Na}^{+}$-dependent neutral amino acid transport system [23]. It is transported in the blood bound to albumin, as low molecular weight compounds, and as part of selenoproteins (ie, selenoprotein $\mathrm{P}$ and glutathione peroxidase) [24]. Because cells do not discriminate between methionine and SeMet, SeMet can be incorporated nonspecifically into proteins in exchange for methionine (Fig. 1). This incorporation likely accounts for the observed dose-dependent increase in tissue Se concentrations when diets are supplemented with SeMet compared with other chemical forms of Se [25]. Moreover, a greater percentage of SeMet is incorporated nonspecifically into body proteins in place of methionine when dietary methionine is low [26]. This nonspecific incorporation into body proteins also provides a means of reversible Se storage in organs and tissues. However, SeMet is usually converted to SeCys through transsulfuration. Although SeCys is found at the active site of proteins, preformed SeCys cannot be incorporated directly into selenoproteins.

Organic and inorganic forms of Se are reduced in the presence of glutathione to generate hydrogen selenide $\left(\mathrm{H}_{2} \mathrm{Se}\right)$, which serves a central role in Se metabolism (Fig. 1). $\mathrm{H}_{2} \mathrm{Se}$ is an extremely reactive molecule that is methylated to render it inert, or converted to selenophosphate for selenoprotein biosynthesis. Oxidation of $\mathrm{H}_{2} \mathrm{Se}$ can generate superoxide and reactive oxygen species. To prevent this, $\mathrm{H}_{2} \mathrm{Se}$ is methylated to methylselenol, which can be reversibly converted back to $\mathrm{H}_{2} \mathrm{Se}$. Methylselenol can be further methylated to dimethylselenide and trimethylselenonium ion, which are excreted in the breath and urine, respectively.

Evidence suggests that it is the methylated forms of Se, particularly methylselenol, that may be important in cancer prevention [27-30]. Se compounds that enter the metabolic pathway beyond the $\mathrm{H}_{2} \mathrm{Se}$ pool have potent anticarcinogenic effects [28]. In addition, Se compounds that can be directly methylated to methylselenol (ie, Se- methyl-selenocysteine and selenobetaine) are more efficacious than selenite in cancer prevention $[28,29]$. Arsenite, which competes with Se for methyl groups, nearly abolishes the protective effect of selenite [30]. Thus, evidence suggests that in addition to 


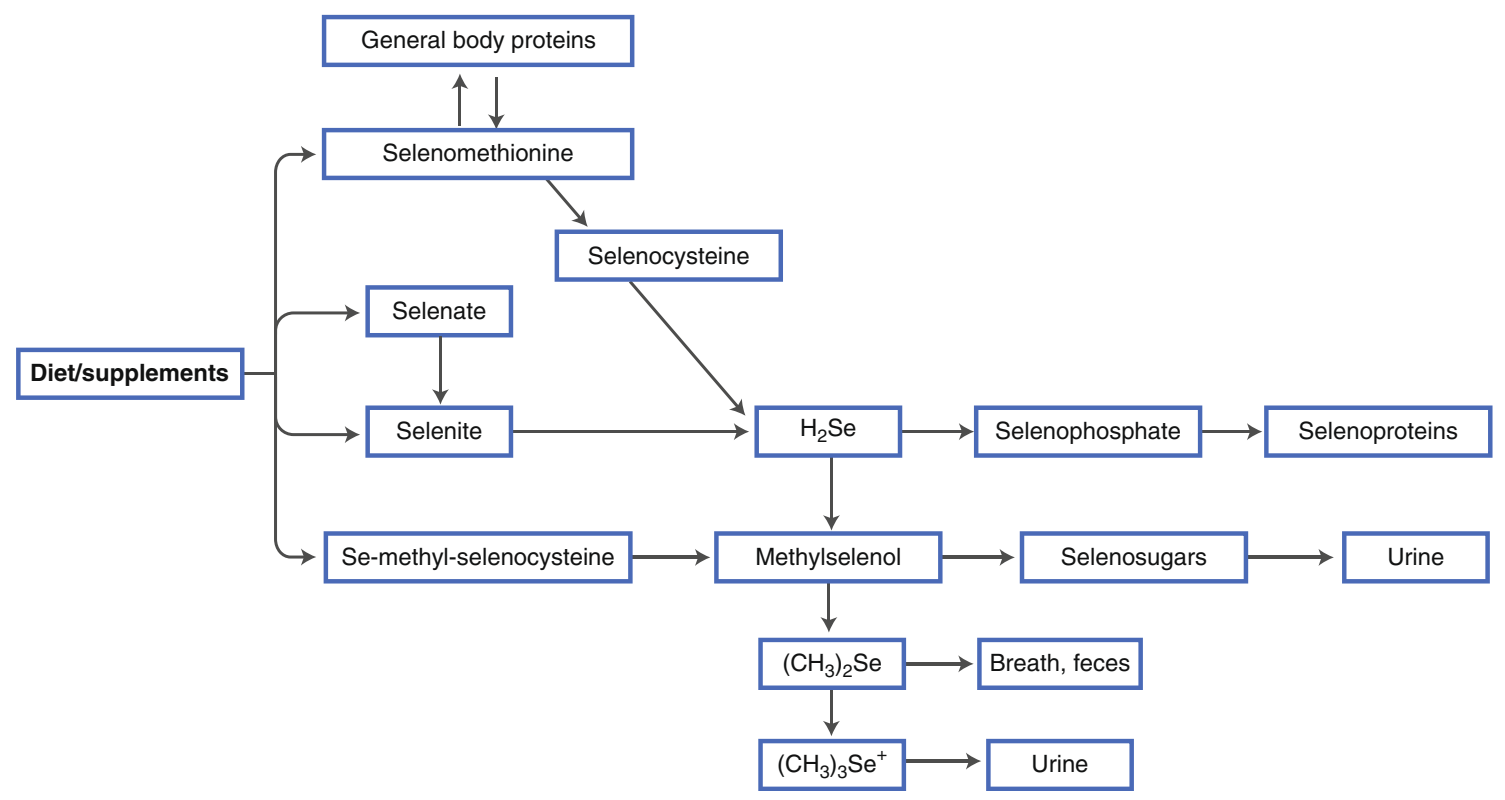

Fig. 1 Metabolism of selenium (Se) compounds found in the diet. Selenomethionine can be nonspecifically incorporated into general body proteins in place of methionine or converted to selenocysteine. Selenocysteine and selenite undergo glutathione-dependent reduction to hydrogen selenide $\left(\mathrm{H}_{2} \mathrm{Se}\right) . \mathrm{H}_{2} \mathrm{Se}$ can then be utilized as a precursor to the synthesis of selenoproteins or undergo methylation to form methylselenol. Se-methyl-selenocysteine is a direct precursor for

selenoproteins, low molecular weight Se species such as methylselenol may play an active role in cancer prevention.

\section{Selenium and Cancer}

\section{Animal Studies}

Extensive experimental evidence indicates that Se supplementation reduces the incidence of cancer in animals. Se supplementation in the diet or drinking water inhibits initiation and/or post-initiation stages of liver, esophageal, pancreatic, colon, and mammary carcinogenesis and spontaneous liver and mammary tumorigenesis [31, 32]. Supplementation during cancer initiation is more efficacious than during the later stages of carcinogenesis [33]. However, Se has beneficial effects against tumor promotion/progression. High-dose Se supplementation (3 ppm in the drinking water) inhibits the progression of hormone-refractory prostate cancer and the development of retroperitoneal lymph node metastases through an inhibition of angiogenesis [34]. Similarly, high-Se soy protein had a greater inhibitory effect than lowSe soy protein on pulmonary metastasis of melanoma cells in mice [35]. However, it is difficult to extrapolate from studies in experimental animals to humans, as animal studies generally have used doses at least 10 times greater than those required to prevent clinical signs of deficiency, which, on a methylselenol. Methylselenol formation has been associated with cancer suppression. Methylselenol can be converted back to $\mathrm{H}_{2} \mathrm{Se}$ or undergo further metabolism to selenosugars, which are excreted in the urine or methylation to form dimethylselenide $\left(\left[\mathrm{CH}_{3}\right]_{2} \mathrm{Se}\right)$ and trimethylselenonium ion $\left(\left[\mathrm{CH}_{3}\right]_{3} \mathrm{Se}^{+}\right)$, which are excreted in the breath and urine, respectively

per-unit body weight basis, are considerably higher than most human Se intakes.

Male beagle dogs, a species that spontaneously develops prostate cancer, more closely reflect the human situation. Studies in these dogs revealed that supplementation with $\mathrm{Se}$ as SeMet or high-Se yeast for 7 months significantly reduced DNA damage and unregulated epithelial cell apoptosis in the prostate compared with dogs with non-supplemented diets [36]. However, a "U-shaped" dose response was evident, and those dogs with high Se status to begin with had adverse effects from increased SeMet [37]. Further study of the process of carcinogenesis within the prostate of animal species vulnerable to spontaneous cancer development may provide important insights into the putative anticancer mechanisms of Se and identify biomarkers that predict the prostate's response to $\mathrm{Se}$.

\section{Epidemiologic Studies}

Evidence for the cancer protective effects of Se in humans was initially obtained by means of ecological and correlational studies. Geographic correlation data in different regions worldwide and in the United States have noted an inverse association between Se levels in forage crops or diet and cancer mortality in the same area [4, 38-40]. Furthermore, statistically significant inverse associations were obtained when cancer mortalities were correlated with 
the blood Se levels of healthy donors in different US cities [41], as well as with the apparent dietary Se intakes in different countries [38]. In China, the mean Se concentrations in blood samples drawn from healthy adults in 24 regions were compared with the corresponding cancer mortality rates. Strong and significant inverse correlations were observed for overall cancer mortality $(r=-0.62)$, particularly for stomach and esophagus [40]. These studies suggested significant protective effects of Se against major forms of cancer. However, other dietary and non-dietary factors that differ among these regions may account for this association.

Subsequently, several case-control studies were performed to investigate the correlation between $\mathrm{Se}$ status and cancer susceptibility. In these studies, Se levels in blood, serum, hair, or toenails were compared between healthy individuals and those of cancer patients. In most cases, a lower Se status in patients compared with controls was reported [42, 43]. However, a few casecontrol studies detected no difference between the two groups or even higher tissue $\mathrm{Se}$ in cancer patients. The inverse associations between short-term biomarkers of Se exposure, such as serum or plasma Se levels, and cancer stage and progression observed in some casecontrol studies suggest that Se status can be utilized in the diagnosis and prognosis of cancer [44, 45]. Some cohort studies have indicated that individuals with preclinical disease may also have lower serum Se concentrations. Interestingly, individuals had lower serum $\mathrm{Se}$ concentrations 4-7 years prior to the appearance of lung [46] or thyroid tumors [47]. However, other studies have not confirmed an association between serum Se concentrations and preclinical disease [48, 49]. More recently, toenail selenium levels were found to be inversely associated with levels of chromosomal damage following exposure to $\gamma$ irradiation as assessed by the micronucleus test in female BRCA1 mutation carriers, but not in non-carriers, suggesting that Se may also be protective in those individuals at increased risk of developing cancer because of genetic polymorphisms [50].

Although these studies demonstrate that low Se levels occur in certain cancer patients, it does not necessarily mean that this is a risk factor for cancer. Because $\mathrm{Se}$ levels were determined after the diagnosis of cancer, the lower Se levels may be a reflection of Se sequestration by the tumor, other metabolic consequences of the tumor, cancer treatment, or poor dietary Se intake. For example, radiotherapy in breast cancer patients resulted in a significant reduction in plasma Se concentrations $(86.4$ and $47.8 \mu \mathrm{g} / \mathrm{L}$ before and after radiation, respectively) [51 $]$. Thus, low $\mathrm{Se}$ status may be a consequence of food aversions caused by the illness or its treatment rather than being a cause of cancer.

Prospective studies, in which the tissue samples are collected before the onset of the disease, avoid many of the potential problems described above for case-control studies. However, the major disadvantage of prospective studies is that even over a moderately extended period of time, the risk of any given individual developing cancer is generally quite low. Thus, samples must be taken from a large number of individuals, who must then be observed over several years for onset of the disease to allow for an adequate sample size.

In prospective studies, low Se status has been associated with significant increased risks of cancer incidence and mortality. Risk has been twofold to sixfold higher in the lowest compared with the highest tertile or quintile of serum Se concentration [42, 52]. In several of these studies, higher Se status appeared more protective against advanced disease. In contrast, a study by Allen et al. [53] failed to detect significant associations between serum Se concentration and subsequent risk of cancer in the European Prospective Investigation into Cancer cohort, and Hunter et al. [54] did not find a relationship between toenail Se concentrations and risk of breast cancer in the Nurses' Health Study cohort. Moreover, when individuals in Northern Italy were accidently exposed to long-term consumption of high levels of inorganic Se in their drinking water, they had a significant increase in melanoma mortality (OR, 4.15 [95\% CI, $0.21-$ 20.47] and OR, 10.98 [95\% CI, 1.84-36.27] in women and men, respectively) compared with non-exposed individuals in the same municipality [55].

Because epidemiologic studies have failed to consistently link low Se status with increased risk of cancer, metaanalyses and systematic reviews have been conducted to quantitatively summarize the existing epidemiologic literature. Forty-nine prospective observational studies with more than 1 million participants were included in a Cochrane review [56••]. They found that the epidemiologic data supported a reduced cancer incidence (OR, 0.69 [95\% CI, 0.53 $0.91])$ and mortality (OR, 0.55 [95\% CI, 0.36-0.83]) with higher Se exposure. This effect was more pronounced in men (OR, 0.66 [95\% CI, 0.42-1.05]) than in women (OR, 0.90 [95\% CI, 0.45-1.77]). However, it was not possible from these studies to determine that Se level or Se intake was the real reason for the lower risk of cancer in some people.

Genetic polymorphisms may be partially responsible for variations in individual responses to Se. Individuals are found to differ substantially in their ability to increase selenoprotein activity in response to additional dietary $\mathrm{Se}$ [57]. This interindividual variation in selenoprotein levels may be a result of single nucleotide polymorphisms in genes encoding selenoproteins and may determine the efficacy with which individuals can incorporate Se into selenoproteins [58-60]. Furthermore, several epidemiologic studies have shown interactions among single nucleotide polymorphisms in selenoproteins, Se status, and cancer risk [61-66]. 


\section{Human Intervention Studies}

Few intervention trials have looked at Se supplementation without supplementing other nutrients. Three trials in China investigated the efficacy of Se supplementation against primary liver cancer in different high-risk populations [67-69]. In a community of about 21,000 people, supplementation with selenite-fortified salt from 1985 through 1992 resulted in a $35 \%$ decrease in the incidence of primary liver cancer [67]. In a study in which 226 hepatitis B antigen carriers were randomly assigned to $200 \mu \mathrm{g}$ of Se-enriched yeast or a placebo, no cases of hepatocellular carcinoma occurred in the supplemented group after 4 years of supplementation, while 7 cases of hepatocellular carcinoma occurred in the placebo group [67]. Similarly, in a study of 2,065 male hepatitis B antigen carriers, 4 cases of liver cancer occurred in the 1,112 individuals who received $500 \mu \mathrm{g} / \mathrm{d}$ selenite, compared with 57 cases in the 953 placebo controls (relative risk [RR], 0.51 [95\% CI, 0.34-0.77]) [68]. In combination, these studies clearly suggest a protective effect of Se supplementation against liver cancer in China.

The Nutritional Prevention of Cancer trial (NPC), carried out in the United States by Clark and co-workers [70], was the first double-blind, placebo-controlled intervention trial in a Western population and was designed to test the hypothesis that Se supplementation would reduce the risk of skin cancer. This study involved 1,312 patients who were recruited because of a recent history of basal cell and/or squamous cell carcinoma of the skin. Although Se supplementation $(200 \mu \mathrm{g} / \mathrm{d}$ as Se-enriched yeast) was associated with a statistically significant elevated risk of squamous cell carcinoma and of total nonmelanoma skin cancer [71], secondary end point analyses showed that the mineral supplementation resulted in a significant reduction in total cancer mortality $(\mathrm{RR}, 0.5)$; total cancer incidence (RR, 0.63); and incidence of lung (RR, 0.54), colorectal (RR, 0.42), and prostate (RR, 0.37) cancer [60]. Admittedly, the number of cases was low. Participants with baseline plasma Se concentration in the lowest two tertiles $(<121.6 \mathrm{ng} / \mathrm{mL})$ experienced reductions in total cancer incidence, whereas those in the highest tertile showed an elevated incidence (hazard ratio [HR], 1.20 [95\% CI, 0.77-1.86]) [72]. Reanalysis of incidence data through the end of the blinded clinical trial indicated that supplementation significantly reduced lung [73] and prostate [74] cancer only in individuals with the lowest baseline Se concentrations. These results suggest that there may be a narrow window for the most beneficial dose of dietary Se.

Initiated in 2001, the Se and Vitamin E Cancer Prevention Trial (SELECT) was a phase 3, randomized, placebocontrolled human trial to investigate the effects of Se $(200 \mu \mathrm{g} / \mathrm{d}$ as SeMet), vitamin E (400 IU/d as $\alpha$-tocopherol acetate), or both with a planned follow-up of a minimum of
7 years and maximum of 12 years for prostate cancer prevention in 35,533 men [75••]. SeMet was chosen as the form of Se because it was believed to be the major form of Se in the Seenriched yeast used in the NPC trial. SELECT was terminated early (in October 2008) because of both safety concerns (trends toward increased prostate cancer in the vitamin E group and increased diabetes in the Se group) and negative data for the formulations and doses given. Moreover, continued follow-up of the participants found that vitamin E supplementation was associated with a significantly increased risk of prostate cancer (HR, 1.17 [99\% CI, 1.004-1.36]), while the results for selenium alone (HR, 1.09 [99\% CI, $0.93-1.27]$ ) and the combination of vitamin $\mathrm{E}$ and selenium (HR, 1.05 [99\% CI, 0.91-1.24]) were null [76]. Similarly, a recent trial in Canada of 303 men with high-grade prostatic intraepithelial neoplasia randomly assigned to Se $(200 \mu \mathrm{g} / \mathrm{d}$, form not specified), vitamin E (800 IU/d), and soy (40 g/d) also found no effect of supplementation on prostate cancer development (HR, 1.03 [95\% CI, 0.67-1.60]) versus placebo [77]. On the basis of these outcomes, many scientists believe that Se may not be efficacious for prostate cancer prevention.

Rather than considering this trial a failure, scientists should consider why the SELECT trial yielded different results than the NPC study and use this information to better understand who might benefit from Se supplementation and who might be placed at risk. Differences in baseline Se status or formulation of the Se supplement may have contributed to the differences observed between the two studies. In fact, in the SELECT trial, median baseline serum levels were $135 \mathrm{ng} / \mathrm{mL}$, compared with $114 \mathrm{ng} / \mathrm{mL}$ observed in the NPC trial, and $78 \%$ of participants in the SELECT trial would have been classified as being in the upper tertile of baseline Se in the NPC trial (the group that had a nonsignificant increased cancer risk with Se supplementation). Another important difference between the two studies is the form of Se provided. The NPC trial utilized Seenriched yeast, whereas the SELECT trial used SeMet. Although Se-enriched yeast is predominantly SeMet, minor Se compounds in the yeast, such as Se-methyl-selenocysteine, but not SeMet, can be metabolized to $\alpha$-keto acids, which function as histone deacetylase inhibitors and lead to derepression of silenced tumor suppressor proteins [78]. These data suggest that different metabolites may have different biological effects. Moreover, a later analytical study reported that the SeMet distribution in the Se-enriched yeast utilized in the NPC trial only accounted for $27 \%$ of the total Se [79]. Thus, it is possible that the effect of $\mathrm{Se}$ in the NPC trial was not caused by SeMet, but rather by other Se compounds or the combination of Se-containing compounds in the yeast. A better understanding of who might benefit from Se supplementation and who might be placed at risk based on baseline $\mathrm{Se}$ status, genetic polymorphisms in selenoproteins or in 
cancer-related processes, cancer site, dose, and form of $\mathrm{Se}$ is needed.

\section{Conclusions}

Strong preclinical and epidemiologic data suggest that Se may be protective against cancer. Although the mechanisms for this protective effect are not fully understood, potential targets include antioxidant protection by selenoproteins, inhibition of tumor cell growth by low molecular weight metabolites, modulation of cell cycle and apoptosis, and stimulation of DNA repair. Low Se status has been associated with a higher risk of lung, prostate, and colon cancer in cohort studies. However, it is important to account for a variety of confounding factors, such as geographical location, gender, age, cancer site, and genetic susceptibility. Although randomized controlled trials suggest a benefit against liver cancer, results at other sites are not as compelling. Results from clinical trials suggest that only Sedeficient individuals may benefit from Se supplementation leading to decreased risk of cancer. In contrast, such supplementation in Se-replete individuals may even cause higher risk of cancer. Future studies, rather than being large intervention studies focused on cancer incidence as the primary end point, should be smaller, shorter, less expensive, biomarker-based studies that can serve as a link from mechanistic and epidemiologic research to human cancer prevention trials. Moreover, these studies must give careful consideration to baseline Se status, form of Se administered, and genetic polymorphisms in selenoproteins.

Disclosure No potential conflicts of interest relevant to this article were reported.

\section{References}

Papers of particular interest, published recently, have been highlighted as:

- Of importance

-• Of major importance

1. Franke KW. A new toxicant occurring naturally in certain samples of plant foodstuffs. I. Results obtained in preliminary feeding trials. J Nutr. 1934;8:597-608.

2. Nelson AA, Fitzhugh OG, Calvery HO. Liver tumors following cirrhosis caused by selenium in rats. Cancer Res. 1943;3:230-6.

3. Schwarz K, Foltz CM. Selenium as an integral part of factor 3 against dietary necrotic liver degeneration. J Amer Chem Soc. 1957;79:3292-3.

4. Shamberger RJ, Frost DV. Possible protective effect of selenium against human cancer. Can Med Assoc J. 1969;100:682.
5. Rotruck JT, Pope AL, Ganther HE, et al. Selenium: biochemical role as a component of glutathione peroxidase. Science. 1973;179:588-90.

6. Kryukov GV, Castellano S, Novoselov SV, et al. Characterization of mammalian selenoproteomes. Science. 2003;300:1439-43.

7. Panel on Dietary Antioxidants and Related Compounds, Food and Nutrition Board, Institute of Medicine. Dietary Reference Intakes for Vitamin C, Vitamin E, Selenium, and Carotenoids. National Academy Press Washington. 2000; 506.

8. Chun OK, Floegel A, Chung SJ, et al. Estimation of antioxidant intakes from diet and supplements in U.S. adults. J Nutr. 2010;140:317-24.

9. Schubert A, Holden JM, Wolf WR. Selenium content of a core group of foods based on a critical evaluation of published analytical data. J Amer Dietetic Assoc. 1987;87:285-99.

10. Terry N, Zayed AM, deSouza MP, Tarun AS. Selenium in higher plants. Annu Rev Plant Physiol. 2000;51:401-32.

11. Whanger PD. Metabolic pathways of selenium in plants and animals and their nutritional significance. In Nutritional Biotechnology in the Feed and Food Industries. Proceedings of Allteck's 19th Annual Symposium Nottingham. Edited by Lyons TP and Jacques KA. Nottingham University Press; 2003;51-58.

12. Schrauzer GN. The nutritional significance, metabolism and toxicology of selenomethionine. Adv Food Nutr Res. 2003;47:73-112.

13. Rayman MP. The use of high-selenium yeast to raise selenium status: how does it measure up? Br J Nutr. 2004;92:557-73.

14. Ellis DR, Salt DE. Plants, selenium and human health. Curr Opin Plant Biol. 2003;6:273-9.

15. Sors TG, Martin CP, Salt DE. Characterization of selenocystein methyltransferases from Astragalus species with contrasting selenium accumulation capacity. Plant J. 2009;59:110-22.

16. Cai XJ, Block E, Uden PC, et al. Allium chemistry: identification of selenoamino acids in ordinary and selenium enriched garlic, onion and broccoli using gas chromatography with atomic emission detection. J Agric Food Chem. 1995;43:1754-7.

17. Dhillon KS, Dhillon SK. Selenium concentrations of common weeds and agricultural crops grown in the seleniferous soils of northwestern India. Sci Total Environ. 2009;407:6150-6.

18. Zhu YG, Pilon-Smits EA, Zhao FJ, Williams PN, Megarg AA. Selenium in higher plants: understanding mechanisms from biofortification and phytoremeidation. Trends Plant Sci. 2009;14:43642.

19. Whanger P, Vendeland S, Park YC, Xia Y. Metabolism of subtoxic levels of selenium in animals and humans. Ann Clin Lab Sci. 1996;26:99-113.

20. Goldhaber SB. Trace element risk assessment: essentiality vs. toxicity. Regul Toxicol Pharmacol. 2003;38:232-4.

21. Lemire M, Philibert A, Fillion M, et al. No evidence of selenosis from a selenium-rich diet in the Brazilian Amazon. Environ Int. 2011, Epub.

22. Schrauzer GN. Selenomethionine: a review of its nutritional significance, metabolism and toxicity. J Nutr. 2000;130:16536.

23. Vendeland SC, Deagen JT, Butler JA, Whanger PD. Uptake of selenite, selenomethionine and selenate by brush border membrane vesicles isolated from rat small intestine. Biometals. 1994;7:30512.

24. Gao Y, Liu Y, Deng G, Wang Z. Distribution of selenium containing proteins in human serum. Biol Trace Elem Res. 2004;100:10515.

25. Schiobara Y, Yoshida T, Suzuki KT. Effects of dietary selenium species on Se concentrations in hair, blood, and urine. Toxicol Appl Pharmacol. 1998;152:309-14.

26. Waschulewski IH, Sunde RA. Effect of dietary methionine on tissue selenium and glutathione peroxidase (EC 1.11.1.9) activity in rats given selenomethionine. Br J Nutr. 1988;60:57-68. 
27. Davis CD, Finley JW. Chemical versus food forms of selenium in cancer prevention. In: Watson RW, editor. Functional foods \& nutraceuticals in cancer prevention. Ames: Iowa State Press; 2003. p. 55-86.

28. Ip C, Hayes C, Budnick RM, Ganther HE. Chemical form of selenium, critical metabolites, and cancer prevention. Cancer Res. 1991;51:595-600.

29. Ip C, Ganther HE. Activity of methylated forms of selenium in cancer prevention. Cancer Res. 1990;50:1206-11.

30. Ip C, Ganther H. Efficacy of trimethylselenonium versus selenite in cancer chemoprevention and its modulation by arsenite. Carcinogenesis. 1988;9:1481-4.

31. Brozmanova J, Minikova D, Vlckova V, Chovanec M. Selenium: a double-edged sword for defense and offence in cancer. Arch Toxicol. 2010;84:919-38.

32. Gromazinska J, Rszka E, Bruzelius K, et al. Selenium and cancer; biomarkers of selenium status and molecular action of selenium supplements. Eur J Nutr. 2008;47:29-50.

33. Yang H, Fang J, Jia X, et al. Chemopreventive effects of earlystage and late-stage supplementation of vitamin $\mathrm{E}$ and selenium on esophageal carcinogenesis in rats maintained on a low vitamin E/selenium diet. Carcinogenesis. 2011;32:381-8.

34. Corcoran NM, Najdovska M, Costello AJ. Inorganic selenium retards progression of experimental hormone refractory prostate cancer. J Urol. 2004;171:907-10.

35. Li D, Graef GL, Yee JA, Yan L. Dietary supplementation with highselenium soy protein reduces pulmonary metastasis of melanoma cells in mice. J Nutr. 2004;134:1536-40.

36. Waters DJ, Shen S, Cooley DM, et al. Effects of dietary selenium supplementation on DNA damage and apoptosis in canine prostate. J Natl Cancer Inst. 2003;95:237-41.

37. Chinag EC, Shen S, Kengeri SS, et al. Defining the optimal selenium dose for prostate cancer risk reduction: insights from the $\mathrm{u}$-shaped relationship between selenium status, DNA damage and apoptosis. Dose-Response. 2009;8:285-300.

38. Clark LC, Cantor KP, Allaway WH. Selenium in forage crops and cancer mortality in U.S. counties. Arch Environ Health. 1991;46:3742.

39. Shamberger RJ, Tytko SA, Willis CE. Antioxidants and cancer. Part VI. Selenium and age-adjusted human cancer mortality. Arch Environ Health. 1976;31:231-5.

40. Yu S-Y, Chu Y-J, Gong X-G, Hou C. Regional variation of cancer mortality incidence and its relation to selenium levels in China. Biol Trace Elem Res. 1985;67:21-9.

41. Shamberger RJ, Willis CE. Selenium distribution and human cancer mortality. CRC Crit Rev Clin Lab Sci. 1971;2:211-21.

42. Klarod K, Hongsprabhas P, Khampitak T, et al. Serum antioxidant levels and nutritional status in early and advanced stage lung cancer patients. Nutrition 2011, in press.

43. Davis CD, Irons R. Are selenoproteins important for the cancer protective effects of selenium? Current Nutn \& Food Sci. 2005;1:201-4.

44. Avanzini P, Vinceti M, Ilariucci F, et al. Serum selenium concentrations in patients with newly diagnosed lymphoid malignancies. Haematologica. 1995;80:505-11.

45. Deffuant C, Celerier P, Boiteau HL, et al. Serum selenium in melanoma and epidermotropic cutaneous T-cell lymphoma. Acta Derm Venereol. 1994;74:90-2.

46. Knekt P, Marniemi J, Teppo L, et al. Is low selenium status a risk factor for lung cancer? Am J Epidemiol. 1998;148:97582.

47. Glattre E, Thomassen Y, Thoresen SO, et al. Prediagnostic serum selenium in a case-control study of thyroid cancer. Int J Epidemiol. 1989;18:45-9.

48. Wallace K, Byers T, Morris JS, et al. Prediagnostic serum selenium concentration and the risk of recurrent colorectal adenoma: a nested case-control study. Cancer Epidemiol Biomarkers Prev. 2003;12:464-7.

49. Murphy SJ, Anderson LA, Ferguson HR, et al. Dietary antioxidant and mineral intake in humans is associated with reduced risk of esophageal adenocarcinoma but not reflux esophagitis or Barrett's esophagus. J Nutr. 2010;140:1757-63.

50. Kotsopoulos J, Chen Z, Vallis KA, et al. Toenail selenium status and DNA repair capacity among female BRCA1 mutation carriers. Cancer Causes Control. 2010;21:679-87.

51. - Franca CA, Noguiera CR, Ramalho A, et al. Serum levels of selenium in patients with breast cancer before and after treatment of external beam radiotherapy. Ann Oncol. 2011;22:1109-12. This study suggests that cancer treatment can influence serum Se concentrations.

52. Steevens J, van den Brandt PA, Godbohm RA, Schouten LJ. Selenium status and the risk of esophageal and gastric cancer subtypes: the Netherlands cohort study. Gastroenterology. 2010;138:1704-13.

53. Allen NE, Appleby PH, Roddam AW, et al. Plasma selenium concentration and prostate cancer risk: results from the European Prospective Investigation into Cancer and Nutrition (EPIC). Am J Clin Nutr. 2008;88:1567-75.

54. Hunter DJ, Morris JS, Stampfer MJ, et al. A prospective study of selenium status and breast cancer risk. JAMA. 1990;264:1128-31.

55. Vinceti M, Rothman KJ, Beromi M, et al. Excess melanoma incidence in a cohort exposed to high levels of environmental selenium. Cancer Epidemiol Biomarkers Prev. 1998;7:853-6.

56. •• Dennett G, Zwahlen M, Brinkman M, et al. Selenium for preventing cancer. Cochrane Database of Syst Rev. 2011;8: CD005195. This paper provides a comprehensive review and meta-analysis of the prospective studies related to Se and cancer prevention.

57. Brown KM, Pickard K, Nicol F, et al. Effects of organic and inorganic selenium supplementation on selenoenzyme activity in blood lymphocytes, granulocytes, platelets and erythrocytes. Clin Sci (Lond). 2000;98:593-9.

58. Hu YJ, Diamond AM. Role of glutathione peroxidase 1 in breast cancer: loss of heterozygosity and allelic differences in the response to selenium. Cancer Res. 2003;63:3347-51.

59. Diwadkar-Navsariwala V, Diamond AM. The link between selenium and chemoprevention: a case for selenoproteins. J Nutr. 2004;134:2899-902.

60. Kumaraswamy E, Malykh A, Korotkov KV, et al. Structureexpression relationships of the $15-\mathrm{kDa}$ selenoprotein gene. Possible role of the protein in cancer etiology. J Biol Chem. 2000;275:35540-7.

61. Steinbrecher A, Meplan C, Hesketh J, et al. Effects of selenium status and polymorphisms in selenoprotein genes on prostate cancer risk in a prospective study of European men. Cancer Epidemiol Biomarkers Prev. 2010;19:2958-68.

62. Penney KL, Schumacher FR, Li H, et al. A large prospective study of SEP15 genetic variation, interaction with plasma selenium levels, and prostate cancer risk and survival. Cancer Prev Res. 2010;3:604-10.

63. Meplan C, Hughes DJ, Pardini B, et al. Genetic variants in selenoprotein genes increase risk of colorectal cancer. Carcinogenesis. 2010;31:1074-9.

64. Meplan C, Nicole F, Burtle BT, et al. Relative abundance of selenoprotein $\mathrm{P}$ isoforms in human plasma depends on genotype, Se intake and cancer status. Antioxidants \& Redox Signaling. 2009;11:2631-40.

65. Bermano G, Pagmantidis V, Holloway N, et al. Evidence that a polymorphism within the 3'UTR of glutathione peroxidase 4 is functional and is associated with susceptibility to colorectal cancer. Genes Nutr. 2007;2:225-32. 
66. Hu J, Zhou GW, Wang N, Wang YJ. GPX1Pro198Leu polymorphism and breast cancer risk: a meta-analysis. Breast Cancer Res Treat. 2010;124:425-31.

67. Yu SY, Zhu YJ, Li WG. Protective role of selenium against hepatitis B virus and primary liver cancer in Qidong. Biol Trace Elem Res. 1997;56:117-24.

68. Li W, Zhu Y, Yanx X, et al. The prevention of primary liver cancer by selenium in high risk populations. Zhoghua Yu Fang Yi Xue Za Zhi. 2000;34:336-8.

69. Yu SY, Zhu YJ, Li WG, et al. A preliminary report on the intervention trials of primary liver cancer in high-risk populations with nutritional supplementation of selenium in China. Biol Trace Elem Res. 1991;29:289-94.

70. Clark LC, Combs Jr GF, Turnbull BW, et al. Effects of selenium supplementation for cancer prevention in patients with carcinoma of the skin. A randomized controlled trial. Nutritional Prevention of Cancer Study Group. JAMA. 1996;276:1957-63.

71. Duffield-Lillico AJ, Slate EH, Reid ME, et al. Selenium supplementation and secondary prevention of nonmelanoma skin cancer in a randomized trial. J Natl Cancer Inst. 2003;95:1477-81.

72. Duffield-Lillico AJ, Reid ME, Turnbull BW, et al. Baseline characteristics and the effect of selenium supplementation on cancer incidence in a randomized clinical trial: a summary report of the Nutritional Prevention of Cancer Trial. Cancer Epidemiol Biomarkers Prev. 2002;11:630-9.

73. Reid ME, Duffield-Lillico AJ, Garland L, et al. Selenium supplementation and lung cancer incidence: an update of the nutritional prevention of cancer trial. Cancer Epidemiol Biomarkers Prev. 2002; 11:1285-91.

74. Duffield-Lillico AJ, Dalkin BL, Reid ME, et al. Selenium supplementation, baseline plasma selenium status and incidence of prostate cancer: an analysis of the complete treatment period of the Nutritional Prevention of Cancer Trial. BJU Int. 2003;91:608-12.

75. •• Lippman SM, Klein EA, Goodman PJ, et al. Effect of selenium and vitamin $\mathrm{E}$ on risk of prostate cancer and other cancers: the Selenium and Vitamin E Cancer Prevention Trial (SELECT). JAMA. 2009;301:39-51. This paper describes the largest clinical study of Se supplementation for cancer prevention.

76. Klein EA, Tangen CM, Thompson IM, et al. Vitamin E increases the risk of prostate cancer: updated results of the SWOGcoordinated Selenium and Vitamin E Cancer Prevention trial (SELECT). JAMA, 2011, accepted/embargoed.

77. Fleschner NE, Kapusta L, Donnelly B, et al. Progression from highgrade prostatic intraepithelial neoplasia to cancer: a randomized trial of combination vitamin-E, soy, and selenium. J Clin Oncol. 2011;29:2386-90.

78. Lee JI, Nian H, Cooper AJ, et al. Alpha-keto acid metabolites of naturally occurring organoselenium compounds as inhibitors of histone deacetylase in human prostate cancer cells. Cancer Prev Res. 2009;2:683-93.

79. Larsen EH, Hansen M, Paulin H, et al. Speciation and bioavailability of selenium in yeast-based intervention agents used in cancer chemoprevention studies. J AOAC Int. 2004;87:225-32. 